\title{
Analytical Models to Characterize Trade-Offs Between Technological Upgrading and Innovation
}

Cathy Zishang Liu, University of Houston-Downtown, USA

Youn-Sha Chan, University of Houston-Downtown, USA

\begin{abstract}
The authors propose two analytical models to characterize the relationship between technological upgrading and innovation in the oil and gas industry. The first one is an "optimization model" which focuses on the trade-offs between profit maximization and environmental compliance cost. The other has been developed based on "predator-prey" model which captures the dynamics of biological systems. The study contributes to the strategic planning process for sustainable development by providing the insight that optimal allocation process is determined by multiple operational factors, including a firm's competitive ranking among its industrial competitors, industrial consent on the concurrent rate of return on capital investment, the projected demand of oil and gas in future, and a change in environmental compliance cost. Further, the authors add to the robustness of the optimal allocation process by providing binding conditions of the set of solutions.
\end{abstract}

\section{KEYWORDS}

Capital Investment, Corporate Social Responsibility, Environmental Protection, Strategic Planning, Sustainable Development, Technological Advancement

\section{INTRODUCTION}

The oil and gas industry is vital to the United States (U.S.) economy supporting nearly 10.3 million jobs in the US and nearly $8 \%$ of the nation's gross domestic product (American Petroleum Institute [API], 2018). The oil and gas industry spurs global economic growth in both developed and developing countries by supplying 57\% of the commercial energy between 2015 and 2018 (British Petroleum, 2019). Approximately $10 \%$ of the value of the world's stock markets is invested in the oil and gas industry (Deloitte LLP, 2015). To continue to support and expand the industry, the oil and gas trade operates by engagement of exploration, production, refinery, storage, transformation, marketing and serving activities. However, recent degradation of the natural environment raises concerns among corporate America and in turn, companies are starting to realize that sustainable development is the unmistakable pathway for all firms who are currently leaving irreversible environmental footprints on Earth (Bhowmik et al., 2000, J. Gonzalez-Benito \& O. Gonzales-Benito, 2005, Yurtsever \& Firat, 2019). Industrial companies such as those in the oil and gas industry are, to a great extent, responsible for this degradation and must strategically aim to enhance their corporate social responsibility by going beyond profits (Arya, et al., 2019; Tung, et al.,2014). While governments hold primary responsibility to prioritize and incentivize while promoting sustainable development and growth, the private sectors 
and civil societies are critical stakeholders to carry on (Carmichael, 2019; Geels, 2002; Geels, et al., 2017; Nelson \& Allwood, 2021).

The historical technological advancement in the oil and gas industry has always been accompanied with systematic industrial changes. America's oil and natural gas industry spends an average of \$227 billion in investment on America's infrastructure annually (International Energy Agency [IEA], 2020). According to Deloitte LLP (2015), investments in the oil and gas industry range from "mega" to "minor". For example, Deloitte LLP (2015, p.14) reports "as of March 2014, the world's four biggest super-major oil and gas companies were spending roughly $40 \%$ of their capital budgets on megaprojects (those with capital investments of \$1 billion or more)". Notably, it mentions that a full $50 \%$ of $40 \%$ of the capital budget goes to technically complex projects, such as the Gorgon LNG project in Australia, the Pearl GTL project in Qatar, the Kashagan project in the Caspian Sea and the Sakhalin project in Russia. The remaining budgets go to minor projects such as Integrated Project Delivery (IPD) which aims to improve collaboration across the supply chains, Advanced Analytics Project which relies on "big-data" to identify critical factors in the decision-making process, and other projects which mainly improve process rather than develop breakthroughs in technological advancement. For instance, the depletion of light oil reserves has caused the change in the average crude quality. As a result, refineries had to upgrade their physical plants, properties, and equipment to deal with the low API gravity and impurities problems. The investment decision (i.e., major vs. minor) is a challenging operation issue unavoidable for oil and gas companies (Deloitte LLP, 2015).

The term "sustainable development" in oil and gas industry refers to the sustainability of human existence by carefully balancing social, economic, and environmental capital in a continuously changing world (Gross, et al., 2018; Perkins \& Neumayer, 2005; Weyant, 2011). Technologically complex and financially volatile, the oil and gas industry is experiencing tremendous challenges during the sustainable development transformation. The industry has been charged with the responsibility of environmental degradation, including air pollution, acid rain, greenhouse emission, ozone layer depletion and global warming (Hsu, et al., 2013, Zailani, et al., 2012). A challenge in the oil and gas industry and in any heavily regulated sectors which have experienced rapid technological changes and regulation requirements, is the dilemma of how to improve operating efficiencies by balancing profit maximization, while also maintaining environmental protection. Consideration should be taken into account as to if firms should upgrade incumbent, fixed assets to generate quick returns at the cost of relatively high levels of potential environmental hazards or invest in long-term innovative projects in anticipation of becoming a market mover and reduce potential environmental liabilities. Examination of the time it takes for leapfrog technology to become obsolete and whether an optimal mixture between upgrading and long-term innovation/invention effort exists should be considered as well.

Following the anecdotal discussions and extant literature, the authors categorize the investment activities in the oil and gas industry into technological upgrading and innovating. Both upgrade and innovation result in change, and both are attempting to make improvements. Upgrades are typically incremental and an iterative process, as each cycle builds on the previous one. When the incremental approach reaches its limit, some substantial steps must incur to solve a problem the incremental approach fails. This is where innovation plays a role (J. Gonzalez-Benito \& O. Gonzales-Benito, 2005; Gotschol, et al., 2014; Gross et al., 2018; Jensen 2001; Kanter, 2011). When original operation plans do not work out as efficiently as they should be, upgrading is a standard action taken by firms to address an obsolete technology or a particular matrix of equipment. This is a less technologically challenging approach that can provide a quick turnaround. It is a replacement process or maintenance or minor elevation process that does not exceed the bound of current technology. Conversely, innovation is a breakthrough of an entire new technology and fundamentally overhauls the status quo of the current production process. Innovation involves developing something or some processes that did not exist in the past or currently. It will significantly improve future productivity or help the firm enter a new marketplace. There is an assumption that upgrading and innovating activities are distinct from each other by defining the timing of returns they can produce, though there is a realization technological 
upgrading and innovating activities can overlap in reality. However, the authors argue differentiating them by the timing of returns they generate reflects the general expectation and convention of investment process in the oil and gas industry.

To the best of the authors' knowledge, prior studies on the relationship between environmental proactivity and business performance is inconclusive. J. Gonzalez-Benito and O. Gonzalez-Benito (2005) analyze this relationship and the results in part support the argument that environmental management can bring about competitive opportunities for firms. At the same time, some environmental practices can produce negative financial effect. Shahbaz et al. (2020) elucidate the role of firm characteristics in corporate social responsibility (CSR) engagement and corporate performance. They provide empirical evidence that accountable board and the existence of a CSR committee are main drivers for a firm's CSR performance. A better CSR performance does not necessarily transfer into a better financial performance. In the same stream of research, researchers report a reciprocal relationship between environmental management and economically sustainable development. Finding from Shahbaz et al. (2020) indicate that the effect of environmental management on a firm's bottom line is a second-order effect while the primary one is to reduce environmental impact. The increased economic value as a result of environmental protection realized by technological innovation could only be realized in the long term (Gotschol et al., 2014; Hassan, et al., 2020).

In the past, there was a clear line between private and government companies, with the former focusing on profit maximization and the latter being concerned over public welfare and wellness (Ayra et al. 2019). This line has become blurred in recent years with the sprout of corporate citizenship and CSR in recent years (Bartov et al., 2021; Davidson et al.; Schelling,1960). The expanding commitment for corporate America in environmental protection and restoration naturally presents a challenge for firms' strategic planning. With varied objectives and missions beyond profit maximization, there is a question as to how a company should balance between for-profit and not-for-profit activities simultaneously since this can have a direct implication on a firm's decision on technological innovation.

The reminder of the paper starts with discussing the extant literature in Section 2, followed by the presentation of reviewing several analytical models. The first model which is formulated as an optimization problem is described and interpreted in Section 3. The authors reference it as an "optimal model" in this paper. Then a famous dynamical model in biological ecosystem - "predator-prey model" is developed in Section 4 to simulate the dynamical behavior between the technological upgrading and innovating was utilized. The conclusion of the study is included in Section 5.

\section{LITERATURE REVIEW}

\subsection{Dilemmas of Technological Advancement}

Not surprisingly, there is vast amount of research studying the oil and gas industry from multiple angles including exploration, engineering, reserves, transportation, energy conversion, demand and supply, price volatility, economic impact, operating efficiencies, and etc. (Library of Congress, 2021; McKinsey \& Company, 2021). This paper closely relates to the debate on optional planning for technological innovation and environmental protection. It is debatable whether technological innovations can result in competitive advantage or operating efficiencies for an oil and gas firm in spite of the heavy upfront capital requirements. This is because not all technological innovations can be adopted for swift deployment. Some technologies can operate at scale and gain immediate operating efficiencies such as hydropower, solar, and wind. Others, such as hydrogen and carbon capture and storage, could take several decades to make a transition (Fouquet, 2016; Nelson \& Allwood, 2021). There are several multiple layers between a new technological initiative and realized returns. According to Nelson and Allwood (2021), they are: blue skies research (research with no commercial intent), applied development (industrial, academic, commercial research), demonstration (demonstrate technology and develop markets, loss-making, vulnerable to economic conditions), commercialization (production and scales up), innovation trap (safety or technical crises), and diffusion (self-sustaining, 
deployment rate constrained by construction needs). The market context in terms of the rule of supply and demand will bind these layers.

Findings in prior studies (Nelson \& Allwood, 2021; Porter \& Kramer, 2006) indicate that major technological changes require commitment to capital and time, and must wait for social timelines, market conditions and governmental supports to make them happen. For example, Gross et al. (2018) document that it takes about 43 years to gain returns from the investment in nuclear generation, wind energy, and solar energy. Motives and efforts towards technological innovation are affected by these factors: complexity of the technological innovation, the availability of substitutes and knowledge spill over, herding effects among industrial competitors, the size of the demand market, the ability of learn from experience, collaboration activities, and governmental actions (Magat, 1978; Sovacool 2016; Tang 2018). Researchers find devices/equipment are easily updated and replaced in small markets, and new processes can be swiftly deployed in small markets as well (Bent, et al., 2018; Grubler, et al., 2016).

Prior studies (Ambec, et al., 2013; Bromberger, 2011; Porter, 1990). also suggest that the investment in the technological advancement is affected by macroeconomic conditions as well. On the one hand, economic downturns will slow down technology adoption, transfer, and deployment. When the market demand falls for energy related products and services, revenues and profits will decline along with it. However, costs, especially those related to fixed assets and capital investments will stay even sales drop because these costs are fixed and not driven by the volume of sales (e.g., property tax, depreciation of equipment, etc.). Further, governments tend to withdraw or provide less money to support risky research and development activities during economic downturns relative to economic upturns, because governments need to redirect their priorities as part of the governmental efforts to re-boost the economy at downturns. For the oil and gas industry, both effects can suppress its innovative activities because of fewer resources. The downturn could also force firms to myopically focus on survival issues rather than remote competitive advantages (Porter \& Vanderlinde, 1995; Smil, 2016). On the other hand, over-hot economic upturns can also stall innovative activities. This is because the firms could be too busy to fulfill demands for their current products and services, and as a result, do not have enough incentives to devote to expected returns potentially yielded by technological advancements (Beake \& Cole, 2020; Benabou \& Tirole, 2011).

Additionally, the "innovation trap" theory lays out perplexities that arise in the rush to bring new products or technologies or processes to the market. Stark and Thompson (2019) document firms tend to be overly optimistic about the technological formation and diffusion process, ignoring the fact that multiple factors, including uncertain and uncontrollable ones, could nullify the commercialization and profitability of the technological advancement. This phenomenon is also described by Weyant (2011) as the "valley of death", which referred to the unachievable economy of scale when a technological innovation cannot be commercialized. Worse, other researchers (Hug 2009; Rogers 2003) observed that funding problems usually accompany with new technology when it has been demonstrated and theoretically proven to not yet be profitable. Changes in market demand, strategic moves by the industrial competitors, governmental regulations, policies, and funding status could adversely affect returns of a new innovation especially when it struggles to pass the "valley of death" (Hug, 2009). According to Rogers (2003), a firm's relative advantage determines how fast an innovation can pass through the "valley of death". This relative advantage could be price advantages or efficiency over the incumbent technology. Compatibility also speeds up the diffusion of new technology. The higher the compatibility with existing technologies, infrastructures, and institutions, the faster the technological diffusion (Rogers, 2003). Findings by Chandrasekaran et al. (2013) suggested that relative advantage could be achieved by cost reductions during the early years.

Further, researchers document the impact of market characteristics on the duration of the formative and diffusion phases. For example, regarding radical and novel technologies, the new technological diffusion process requires the creation and stabilization of entirely new social, economic, and cultural structure including standards, infrastructures, and social acceptance (Ander \& Kapoor, 2010; Arthur, 
2009). Furthermore, Wilson, et al. (2012) reported that the size of the potential market also matters - a more pervasive market takes longer to penetrate. Echoing this point of view, other researchers reported that developing countries have the later comer advantage and adopt/diffuse innovations faster than developed countries (Lanjouw \& Mody, 1996; Neumayer, 2005). Moreover, they find trade openness influences the rate of technological diffusion positively, although foreign direct investment (FDI) fails to accelerate technological adoption speed in the host country.

Collectively, this strand of literature confirms that technological upgrading or innovating decisions are a strategic and dynamic process, which is affected by the timeline of expected returns, status of competitive ranking, speed of knowledge spillover, changes in market context and changes in governmental actions and country characteristics. It is thus important to model all these factors in when formulizing technological advancement plans in the oil and gas industry. Due to the volatile nature of these factors, any ex-ante investment decision could result in either over or under investment ex-post, therefore, the oil and gas firms need to develop reliable long-lasting strategies to optimize their capital investments. It is less clear on how the intricate relationship of these factors affect the optimization process. This study attempts to shed light on the trade-offs between technological upgrading and innovating in the context of these operating factors.

\subsection{The Technological Innovation and Environmental Protection}

As a driver of economic and social evolution (Bento et al., 2018; Duarte \& Serran, 2021; Nelson \& Allwood, 2021), the oil and gas industry plays a central role in global sustainable development. The diffusion of innovative and efficient technology has far-reaching implications beyond profits for the global economic activity, inequality, and environmental protection. There is extant literature examining the relation between technological innovation and environmental protection. Arya et al. (2019) documented that it becomes increasingly common for hybrid entities with a mission that extends "beyond profit". Pursuing corporate citizenship and CSR has emerged as a priority for more and more firms. Many firms simultaneously value the profits they generate and the concomitant utility they can provide to the stakeholders and society, such as more environmentally friendly products and services. Schelling (1960) examines whether "delegating" decision making to an individual whose objective deviates from pure profit maximization can be a strategic choice. He concludes broader objectives other than profit maximization benefit a firm's growth in the long run. Building on stakeholder theory, Freeman (2010) suggests there is a need for valuing and considering objectives of a firm's diverse stakeholders, not just its equity-holders. These diverse objectives (employee treatment, better products and services, more stakeholders, and environment is only one dimension) include broad CSR, of which environmental protection is an important constituent. Further, researchers document that the presence of diverse objectives firms changes the competition and valuation context in an industry (Hansmann, 1980; Hart, 2003, Matsummura, 1998). For example, helping particular customers, such as offering reduced electricity bills for disadvantaged people and delivering green energy, are the type of activities that not only arise as strategic ramifications, but also can lead to a higher profit margin than conventional operating strategies (Bromberger, 2011; Hino \& Zennyo, 2017; Stevens, et al., 2012). Focusing on the gain of competitive advantage caused by voluntary disclosures, Arya et al. (2019) provides an analytical model showing that the rise of dual-purpose organizations perturbs their purely for-profit rivals, achieves better economic goals, and ensures equilibrium industry composition. The benefits come from the fact that the firm is able to commit to certain irrational and current actions for potential future gains. For example, broader objectives beyond profit maximization can motivate employees better under compensation design (Friedman \& Heinle, 2016; Vickers, 1985). Strategic transfer pricing within internal business segments or collaborative competitors from dual purpose firms could result in higher future market shares (Gox \& Schiller, 2006).

Relating broader objectives beyond profit maximization to the oil and gas industry, a salient one is environmental proactivity. With the growing awareness of climate change and environmental degradation that threatens a human's survival, the oil and gas companies are urged to engage in 
environmentally and socially responsible business practices (Agnolucci \& Arvanitopoulos, 2019; Alam, et al., 2019; Shahbaz et al., 2020). Companies' environmental commitment via technological advancement has become an imperative strategic step in the context of radical competitive scenarios. Researchers are able to distinguish two positions of oil and gas companies: "environmental reactivity, typical of companies that only implement the minimal compulsory changes to meet regulations; and environmental proactivity, typical of companies that voluntarily take measures to reduce their impact on the natural environment" (J. Gonzalez-Benito, \& O. Gonzalez-Benito, 2005, p. 2). To what extent environmental proactivity can improve a firm's competitive ranking in the oil and gas industry has caused controversy.

There are two arguments surrounding the relationship between technological innovation and environmental regulation. Environmental regulation could result in companies being overburdened with the compliance requirements, which increase the cost of environmental protection, reduce funding for direct capital investment, and show the crowding-out effect (Gray \& Shadbergian,1998; Shen et al., 2017). On the other hand, environmental governance could force enterprises to optimize production, improve operating efficiency, and cut costs in the long term (Porter, 1990). The net effect of technological innovation on the firm's benefits could go in both directions. The Pollution Heaven Hypothesis proposed by Walter and Ugelow (1979) argues that stringent environmental regulation will lead polluting companies to modify production decisions and transfer production process to developing countries with low environmental regulation standards. This phenomenon leads to the fact that the environmental regulation increases the production cost, and induces them to speculate and transfer production lines, and does not stimulate them to carry out technological innovation. Research that supports this point of view includes Gray and Shadbergian (1998) which documents a negative correlation between the strictness of environmental regulation and companies' productivity. It also reveals that the benefits from technological innovation cannot compensate for the "compliance costs" of environmental regulation. In addition, Shen et al. (2017) confirms that the existence of the phenomenon of "pollution near transfer" is caused by stricter environmental regulations. Conversely, the Porter Hypothesis states that well-designed environmental regulations can promote regulated companies to carry out more innovative activities (Porter, 1990). Furthermore, technological innovations will increase productivity and improve the innovation level of the whole industry, which will generate noticeable results of innovation offset. Innovation offset will balance the cost of environmental protection, improve productivity, consolidate competitiveness, and eventually promote the firm to gain competitive advantage in the international market (Ambec et al., 2013; Jaffe \& Palmer, 1997; Xie, et al., 2016).

Utilizing the direct acyclic graph model to examine large scale provincial panel data in China, Pan et al. (2019) reveals the relationship among environmental regulation, technological innovation and energy efficiency. They find environmental regulation contributes directly to energy efficiency and this efficiency is realized through technological innovation. Their results also confirm that "a strong environmental regulation is an important guarantee for the construction of a resource-saving and environmental-friendly society" (Pan et al., 2019, p. 428) Nelson and Allwood (2021) suggests companies and governments largely ignore the socially driven mitigation of environmental hazard in favor of technological innovation in the energy sector. Other studies (Naughton et al. 2019; Baker $\&$ Wurgler, 2007) provide some explanations on why companies are overconfident in technological innovation. Naughton et al. (2019) documents time-varying investor sentiment for CSR performance. They find from time to time, investors optimistically reward firms with better CSR performance not justified by the underlying economics of a particular technology. Further, several prior studies have shown that consumers tend to rely on the firm's CSR performance to choose between otherwise similar products and services (Bagnoli \& Watts, 2003; Baker \& Wurgler, 2007; Munsamy et al., 2020). They also tend to rely on CSR performance to choose between otherwise similar investment opportunities (Friedman \& Heinle, 2016; Naughton et al., 2019). The sentiment of consumers and 
investors in the product markets and capital markets provides incentive for the oil and gas companies to commit to environmental protection.

Stevens et al. (2012) indicate many industrial firms have moved beyond complying with governmental regulations by adopting a proactive environmental management approach. Tung et al. (2014) identify organizational factors that influences a firm's environmental management. Those factors include top management support, training, employee participation, and teamwork. Their findings suggest organizations that provide more training are able to achieve higher effectiveness in regard to environmental management process. The link of performance to rewards can also enhance the effectiveness of the environmental management processes. Using data from central and eastern European countries, Duarte and Serrano (2021) document that domestic environmental regulations for compliance with the new European Union (EU) environmental acquis results in huge technological investments to improve energy efficiency and replace coal energy in these countries. Their results highlight the importance of considering both demand and technological changes for an effective formulation of environmental policy at the global level. Ma, et al. (2011) classifies environmental regulation tools as command control environmental regulation and market incentive environmental tool. They empirically study the influence of these two tools on technological innovation using the method of hierarchical regression. Their results indicate that command control environmental regulation does not have a significant impact on technological innovation and that the market incentive environmental regulation has a significant positive impact on technological innovations.

\section{OPTIMAL MODEL}

In this section, the authors present a formulation and its closed-form solution for the optimal model and also give the model implications after the closed-form solution has been derived.

\subsection{Formulation and Exact Solution of Optimal Model}

Given the key features discussed on technological formation process in the oil and gas industry, there is an assumption there are $\mathrm{N}$ competitors in the oil and gas industry indexed by $\mathrm{i}=1, \ldots \mathrm{N}$. One firm out of the $\mathrm{N}$ firms needs to decide how to allocate a fix amount of money between two capital projects. Though the total amount that can be invested is fixed, the firm is allowed to flexibly allocate a percentage of the funds between these two projects. For example, the firm can invest $0 \%(-10 \%)$ of the fixed amount in Project 1, and 100\% (110\%) in Project 2. The negative percentage indicates the firm actually sells its existing assets and uses the proceeds from the sale to invest in Project 2. Investments will be committed at date 1 . Depending on whether it is an upgrading or innovating project, returns on the investments will be generated across different timelines. Project 1 (upgrading), focusing on investing in existing technology will realize its returns in day 1 . Project 2 (innovating), focusing on long-term leapfrog technological innovation will take longer time to develop and realize its returns. Therefore, the returns from Project 2 will be realized on day 2. At day 1, when the allocation of capital expenditure decision needs to be made, there is liquid investment assets that competitors can trade, sell, and buy assets and technology without any restrictions. The firm's existing assets can either be expanded via Project 1 or be sold and settled with proceeds to be invested in Project 2 . The firm has the flexibility to invest in either project or a mix of the two projects. In addition, the rate of return of Project 1 on day 1 , or $r_{1}$, is public information known to all parties because of the existence of a very liquid assets market. However, the expected rate of return of project 2, or $r_{2}$, is uncertain because of uncertainties caused by industrial competition for technological advancement and the volatility caused by the supplies and demands of the future markets. For example, some energy companies slowed down their production by shutting down some transporting pipelines when navigating the pandemic 
due to the decline in demand. Consequently, the overall rate of return of the pipelines suffered. The authors believe this setting characterizes the real economics of upgrading vs. innovation.

Upgrading is a standard action taken by firms to address an obsolete technology or a particular matrix of equipment and infrastructure that are not working as efficiently as they should be. This is a less technologically challenging approach that can provide a quick turnaround. It is a replacement process or maintenance or minor elevation process that does not exceed the bound of current technology. Conversely, innovation is a breakthrough of an entirely new technology and fundamentally overhauls the status quo of the current production process. It involves developing something, or some processes, that did not exist in the past or does not exist at the current moment. It will significantly improve future productivity or help the firm enter a new marketplace. Generally speaking, firms that have successfully invested in innovation have the chance to be a market mover and gain significant competitive advantages, which can convert to profits. This type of investment requires significant time to execute properly and carries a higher risk of failure due to the challenging nature of technological innovation and scientific discoveries. To further approximate what happens in the real world of oil and gas industry, the authors assume Project 1 (upgrading) has a relatively high level of legal liabilities for environmental compliance. Upgrading maintains obsolete technology and regulatory bodies increase environmental regulations over time. For example, many environment lawsuits were the results of lack of technological innovation during long-stand operational practice (Alaska Department of Environmental Conservation v. Environmental Protection Act [EPA], 540 U.S. 461, 2004), the Supreme Court found that the EPA has authority to overrule state agency decisions under the Clean Air Act that EPA can require a company to use the "best available controlling technology" to prevent pollution. ExxonMobil was under a lawsuit in 2009 due to a gasoline leak in a service station caused by obsolete technology. A once standard construction materials - asbestos generated labor related lawsuits for retrospective liabilities since 1993). The examples indicate without technological advancement, products or services could stay with low quality, which increases the likelihood of lawsuit, even subjecting firms for retrospective product or service liabilities. Project 2 (innovating) has a relatively low level of legal liabilities for compliance because it results in much advanced technology that will deliver a better job in terms of environmental smartness. For example, electrical cars significantly reduce the air pollution. Therefore, the success in Project 2 will reduce the likelihood that the firm will be sued due to violation of environmental regulations. The study assumes any additional investments in oil and gas industry will generate costs due to the environmental compliance. In other words, environmental compliance costs are inevitable and always co-exist with any investment. Whenever there is an investment, there will be environmental compliance costs. The environmental compliance costs serve as negative components when calculating the total net return of the firm's investment.

The study sets $\mathrm{U}$ for the investment amount allocated to Project 1 and $\mathrm{V}$ for the investment amount allocated to Project 2 by the firm. Thus, ex ante, the expected return of the firm, which has decided the allocated amount among two projects, is a random variable that can be described by:

$$
\tilde{C}=u_{1} r_{1}+u_{2} \widetilde{r}_{2}-H\left(u_{1}, u_{2}\right)
$$

where $H$ is the environmental compliance costs determined jointly by two variables of $u_{1}$ and $u_{2}$. It is assumed high level of legal risk converts to high environmental compliance cost. If the firm makes investments, regardless of if it is Project 1 or Project 2, there will always be accompanying environmental compliance costs with the investments. In other words, upgrading and innovation can only reduce the environment hazard but cannot fully eliminate the environmental hazard. As long the oil and gas companies operate, the environmental costs will be there. The firm's goal is to minimize them as much as possible, but the costs will always be greater than zero regardless how little it is. 
The study maximizes $\tilde{C}$ which represents the expected returns from the two projects over two time periods under the following constraint:

$u_{1}+u_{2}=s$

for some fixed $s$ (i.e., the firm has limited resources to invest which reflects the reality that oil and gas firms usually make capital expenditures bounded by the annual budget. The study explores how to find the optimum investment allocation that solves:

$u_{1}^{*}, u_{2}^{*}=\arg \operatorname{Max}\left\{u_{1} r_{1}+u_{2} \tilde{r}_{2}-H\left(u_{1}, u_{2}\right)\right\}$ suchthat $u_{1}+u_{2}=s$

Using the method of Lagrange multipliers, the study first constructs the Lagrangian as:

$C_{L}=u_{1} r_{1}+u_{2} \tilde{r}_{2}-H\left(u_{1}, u_{2}\right)-\lambda\left(u_{1}+u_{2}-s\right)$

where $\lambda$ is the Lagrange multiplier. Then the study expands the first-order optimum condition of $C_{L}$ with respect to $u_{1}, u_{2}$ and $\lambda$ as follows:

$\frac{\partial C_{L}}{\partial u_{1}}=r_{1}-\frac{\partial H}{\partial u_{1}}-\lambda=0$

$\frac{\partial C_{L}}{\partial u_{2}}=\tilde{r}_{2}-\frac{\partial H}{\partial u_{2}}-\lambda=0$

$\frac{\partial C_{L}}{\partial \lambda}=s-u_{1}-u_{2}=0$

Canceling $\lambda$ from equations (3) and (4), the study obtains:

$\frac{\partial H}{\partial u_{1}}-\frac{\partial H}{\partial u_{2}}=r_{1}-\tilde{r}_{2}$

Equation (6) reveals that the difference of the sensitivity of the cost with respect to the investment in upgrading and innovation must be matched by the difference between their corresponding rate of returns. The linear functional relationship with respect to the investment, as shown in equation (5), joined by the linear functional relationship with respect to the sensitivity to the investment, as shown in equation (6), jointly determines the optimal investment allocation, which is the solution of equation (2). 
It is widely assumed in accounting literature that the cost function, $H\left(u_{1}, u_{2}\right)$, is strictly convex (DeMarzo \& Duffle, 1995; Diaz et al., 2015; Kanodia et al., 2000; Melumad et al., 1999). An example of such cost function, yet without loss of generality, can be written as:

$H\left(u_{1}, u_{2}\right)=\frac{1}{2} \alpha u_{1}^{2}+\frac{1}{2} \beta u_{2}^{2}+\gamma$,

where $\alpha$ and $\beta$ are coefficients assigned to the investment of the upgrading project and the innovation project, respectively, and $\gamma$ is a common overhead cost. Subject to (7), equation (6) becomes:

$\alpha u_{1}-\beta u_{2}=r_{1}-\tilde{r}_{2}$.

Now combining equations (8) and (5), the authors obtain the optimum allocation, as the solution to equation (2), which reads:

$u_{1}^{*}=\frac{\beta s+\left(r_{1}-\tilde{r}_{2}\right)}{a+\beta}$

$u_{2}^{*}=\frac{\alpha s-\left(r_{1}-\tilde{r}_{2}\right)}{\alpha+\beta}$

This set of solution indicates that the necessary and sufficient condition for $u_{1}^{*} \geq u_{2}^{*}$ is $\tilde{r}_{2} \leq r_{1}-\frac{1}{2}(\alpha-\beta) s$. Likewise, the necessary and sufficient condition for $u_{1}^{*}<u_{2}^{*}$ is $\tilde{r}_{2}>r_{1}-\frac{1}{2}(\alpha-\beta) s$.

\subsection{Implications of the Optimal Model}

The authors first review the setting up of variables before interpreting the results from equation (9) and (10). $u_{1}^{*}\left(u_{2}^{*}\right)$ is the optimal investment allocation on short-term (long-term) project of upgrading (innovating). $r_{1} i s$ the rate of return on upgrading projects which is public known on day 1 among industrial peers given the existence of a well liquid asset market. $\tilde{r}_{2}$ is the expected rate of return on innovating project which not only depends on the extent of the success of the innovating project (how leapfrogging it is compared to those of the industrial competitors) but also depends on the uncertain demand and supply in the markets. $\alpha$ and $\beta$ represent the proportional percentage of environmental compliance cost relative to the allocated investment, and $\alpha$ will resolve its uncertainty early than $\beta$. Moreover, since innovating project will be more technologically advanced, if the environment protection requirement will not change by political reasons, then on average, $\alpha$ will be greater than $\beta$. In other words, upgrading is less environmental smart than innovating. $\mathrm{S}$ is the fixed amount that is subject to the allocation between $u_{1}$ and $u_{2}$.

Given the setting up of the variables, the following immediate interpretations were obtained: 


\subsubsection{Interpretation 1}

The optimal allocation is determined by the investment amount, magnitude of the difference in rate of returns between the two projects, and the evolution of environmental compliance cost within two periods. In theory and perhaps in reality, the values of key parameters are estimable and accessible. For example, the proportional percentage of environmental compliance cost relatively to the allocated investment (i.e., $\alpha$ and $\beta$ ) can be empirically obtained by utilizing the archival operating data from the companies in oil and gas industry, though some proprietary information perhaps will be kept for internal use by the firm itself. Many oil and gas companies voluntarily disclose their environmental compliance cost in their CSR reports. S relates to the firm's internal budgeting and capital expenditure policies. $r$ can be observed from the industry consent. The oil and gas companies hold conferences, workshops, and seminars to promote and share industrial consent and norms. The rate of return for certain types of upgrading projects is common industry knowledge to industrial insiders. On the other hand, if the government can improve the data sharing, revealing, and coordinating practices among these companies, then the strategic planning on each individual firm's investment opportunity will become more efficient.

\subsubsection{Interpretation 2}

$\alpha$ and $\beta$ stays as the denominator of the solution. The authors observe there are many competitive players in the oil and gas industry. The collective efforts of major oil and gas giants take up significant shares of the worldwide economy. It is rational to assume that the investment amount from these crucial industry players will be much greater than the firms with small market shares. If it is held the parameter values relatively constant, the regulatory requirements to environmental protection do not go stringent (i.e., $\beta$ remains positive), and the innovating project does not significantly succeed than the updating one, $\left(r_{1}-\tilde{r}_{2}\right.$ approaches 0$)$, then because on average, $\alpha$ is greater than $\beta$, larger firms tend to invest more (i.e., larger $\mathrm{S}$ ) because of their deeper pockets. $\beta S$ will be smaller than $\alpha \mathrm{S}$. As a result, the authors conclude that larger oil and gas firms tend to invest more on innovating project than smaller firms. If the innovating project is significantly more successful than the upgrading project, and the expected market demand with an upward trend (i.e., $\tilde{r}_{2}$ is much greater than $r_{1}$ ), then the optimal allocation investment indicates that the firm should invest more in the innovating project. When the innovating project is not a significant success and the market demand bleaches ( $r_{1}>\tilde{r}_{2}$ ), then the optimal allocation scheme is blurring and losing its tension (i.e., it does not matter how firms allocate its investment in terms of expected returns).

\subsubsection{Interpretation 3}

$\beta$ changes over time due to the change of the environmental protection caused by the political regime. $\beta$ could become larger than $\alpha$ (i.e., the speed of the technological innovation still falls behind the faster environmental protection requirements, perhaps caused by the change in political regimes, for example, the Keystone PL Pipeline case). In this context, if the innovating project does not significantly succeed than the updating one, $\left(r_{1}-\tilde{r}_{2}\right.$ approaches 0$)$, the effect of the role of major industrial players in investment decision becomes blur. They may or may not have incentives to invest more on innovating project than in upgrading project. If the innovating project is significantly successful than the upgrading project, and the expected market demand with an upward trend (i.e., $\tilde{r}_{2}$ is much greater than $r_{1}$ ), then the optimal allocation investment indicates that the firm could still invest more in the innovating project, even if the potential environmental compliance cost could go up in the near future. However, when the innovating project is not a significant success and the market demand bleaches $\left(r_{1}>\tilde{r}_{2}\right)$, then $\beta S+\left(r_{1}-\tilde{r}_{2}\right)$ will be greater than $\alpha \mathrm{S}-\left(r_{1}-\tilde{r}_{2}\right)$, it suggests that the firms should invest more in upgrading project than in innovating project. This conclusion 
suggests that stringent regulatory requirements could have negative side effect of strangling innovation incentives for firms.

\subsubsection{Interpretation 4}

The model indicates that the necessary and sufficient condition for $u_{1}^{*} \geq u_{2}^{*}$ is $\tilde{r}_{2} \leq r_{1}-\frac{1}{2}(\alpha-\beta) s$. Likewise, the necessary and sufficient condition for $u_{1}^{*}<u_{2}^{*}$ is $\tilde{r}_{2}>r_{1}-\frac{1}{2}(\alpha-\beta) s$. Once the parameter values can be obtained by the operating data, the binding effect of the solutions can be achieved.

\section{PREDATOR-PREY MODEL}

As the relationship between "upgrading" and "innovating" has a very similar behavior as the relationships between predator and prey, the authors propose to use the Lotka-Volterra equations, to model the relationship between "upgrading" and "innovating". It is the authors' assumptions that this is the first study using predator-prey model to examine upgrading and innovating in oil and gas industry. This is a dynamical model because both the technological innovation and upgrading are functions of time. The same symbols will continue to be utilized as in the "optimal model": $u_{1}(t)$ is the investment amount allocated to Project 1 , and $u_{2}(t)$ is the investment amount allocated to Project 2 by the firm. Both $u_{1}(t)$ and $u_{2}(t)$ are functions of time $t$ now. Moreover, the dynamical model does not assume that the sum of $u_{1}(t)$ and $u_{2}(t), s(t)=(t)+u_{2}(t)$, is a fixed amount as in the optimal model. Project 1 (upgrading) focuses on investing in existing assets which realize its returns in day 1 , and Project 2 (innovating) focuses on long-term leap-frog technological innovation which takes longer time to develop and realize its returns. In determining what kind of dynamical relationship(s) will be between $u_{1}(t)$ and $u_{2}(t)$, the authors propose the predator-prey model and its "modified" version.

\subsection{Formulation of the Predator-Prey Model}

To make the predator-prey model be more realistic, it is assumed that $u_{1}(t)$, the investment amount allocated to Project 1 , is more "profit oriented", and $u_{2}(t)$, the investment amount allocated to Project 2 , is more "environment friendly". The gain (or increase) of $u_{1}(t)$ relies on the existence of $u_{2}(t)$; that is, without reasonable environment's support, there is limited gain of $u_{1}(t)$. However, if $u_{1}(t)$ is gaining too much, then it will hurt the environment; that is, $u_{2}(t)$ is "sacrificing", so the relationship between $u_{1}(t)$ and $u_{2}(t)$ is similar to the behavior between predator and prey. "Predator" is used to represent $u_{1}(t)$, the investment amount allocated to Project 1, and "prey" to represent $u_{2}(t)$, the investment amount allocated to Project 2 by the firm.

The classical predator-prey model is governed by a set of differential equation that is also called "Lotka-Volterra" equation (Devaney, 2018; Strogatz 1994), and it is a set of two first-order nonlinear, ordinary differential equations. The Lotka-Volterra equation has been used to describe the dynamics of ecological or biological systems in which two species interact, one as a predator and the other as a prey. However, the authors generalize the Lotka-Volterra equation and use the following set of equation:

$$
\frac{d u_{1}(t)}{d t}=F\left(u_{1}(t), u_{2}(t)\right)=\alpha 1 u_{1}(t)+\alpha 2 u_{2}(t)+\alpha 3 u_{1}(t) u_{2}(t)
$$




$$
\frac{d u_{2}(t)}{d t}=F\left(u_{1}(t), u_{2}(t)\right)=\beta 1 u_{1}(t)+\beta 2 u_{2}(t)+\beta 3 u_{1}(t) u_{2}(t)
$$

where $\alpha_{1}, \alpha_{2}, \alpha_{3}, \beta_{1}, \beta_{2}$, and $\beta_{3}$ are some constants. The classical Lotka-Volterra equation does not include $\alpha_{2}$ and $\beta_{1}$. The study modified the Lotka-Volterra equation so that the relationship between $u_{1}(t)$ and $u_{2}(t)$ is not exactly the same as predator and prey. However, the dynamical behavior between $u_{1}(t)$ and $u_{2}(t)$ can be captured by the "modified" Lotka-Volterra equation.

\subsection{Simulation Results}

With different choices of the constants $\alpha_{1}, \alpha_{2}, \alpha_{3}, \beta_{1}, \beta_{2}$, and $\beta_{3}$, the dynamical behavior between $u_{1}(t)$ and $u_{2}(t)$ are different. In most of classical dynamical analysis, one would like to find all possible "equilibrium point(s)", or different types of "final status", and the analysis requires some mathematical details and derivation. To save the mathematical derivation, the authors chose different values of $\alpha$ 's and $\beta$ 's to explore all different types of an equilibrium situation. In total, four cases are considered with two cases of classical Lotka-Volterra equation and two modified Lotka-Volterra equations. While there are many more other cases for consideration, for purposes of this study, only presented are the ones thought to have a physical meaning associated with the dynamics between technological innovation and upgrading.

\subsubsection{Case I-Classical Lotka-Volterra Case}

In this simulation the authors consider the classical Lotka-Volterra dynamical system between $u_{1}(t)$ and $u_{2}(t)$. The choice of $\alpha$ 's and $\beta$ 's is:

$\alpha_{1}=-0.6, \alpha_{2}=0, \alpha_{3}=0.5, \beta_{1}=0, \beta_{2}=0.4$, and $\beta_{3}=-0.5$, and the system becomes:

$$
\begin{aligned}
& \frac{d u_{1}(t)}{d t}=-0.6 u_{1}(t)+0.5 u_{1}(t) u_{2}(t) \\
& \frac{d u_{2}(t)}{d t}=0.4 u_{2}(t)-0.5 u_{1}(t) u_{2}(t)
\end{aligned}
$$

The simulation results are shown in Figures 1 to 5. Figures 1 and 2 record that $u_{1}(t)$ and $u_{2}(t)$ as a function of time $t$, respectively. The graphs of $u_{1}(t)$ and $u_{2}(t)$ are plotted together in Figure 3 .

Clearly, the authors observe that $u_{1}(t)$ and $u_{2}(t)$ are behaving like predator and prey. Additional observations are made from Figures 1, 2, and 3:

(1) Figures 1 and 2 provide a benchmark status. Both $u_{1}(t)$ and $u_{2}(t)$ are periodic functions.

(2) When $u_{1}(t)$ approaches to zero, then $u_{2}(t)$ attains its maximum.

(3) When $u_{1}(t)$ increases, then $u_{2}(t)$ decreases. However, as $u_{2}(t)$ decreases to certain level, then $u_{1}(t)$ also decreases.

(4) This cycle appears repeatedly, which plots $u_{1}(t)$ and $u_{2}(t)$ in Figures 4 and 5 . In Figure 4, a dynamical "cycle" is observed, and in Figure 5, the "motion" of the dynamical "cycle" is observed.

\subsubsection{Case II - Second Lotka-Volterrra Case}

In this simulation, the (classical) Lotka-Volterra dynamical system is still considered by choosing different $\alpha$ 's and $\beta$ 's: 
Figure 1. $u_{1}(t)$ as a function of time $t$

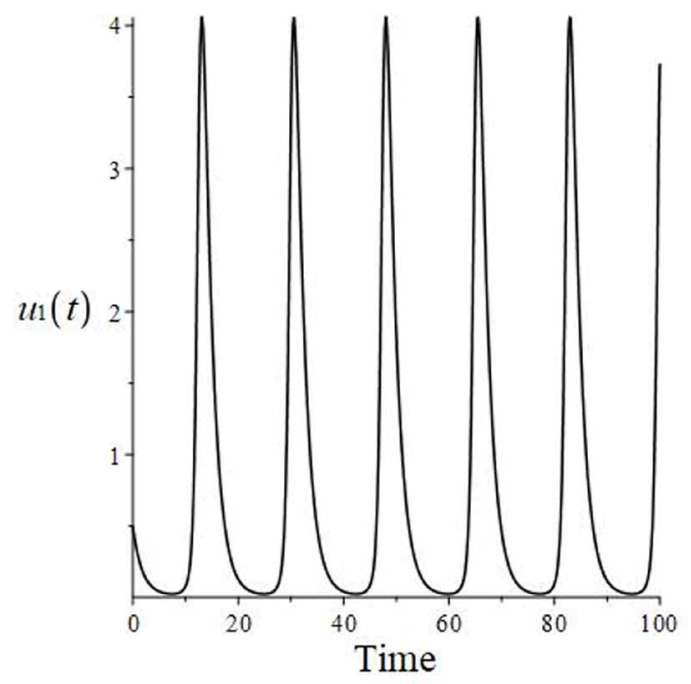

Figure 2. $u_{2}(t)$ as a function of time $t$

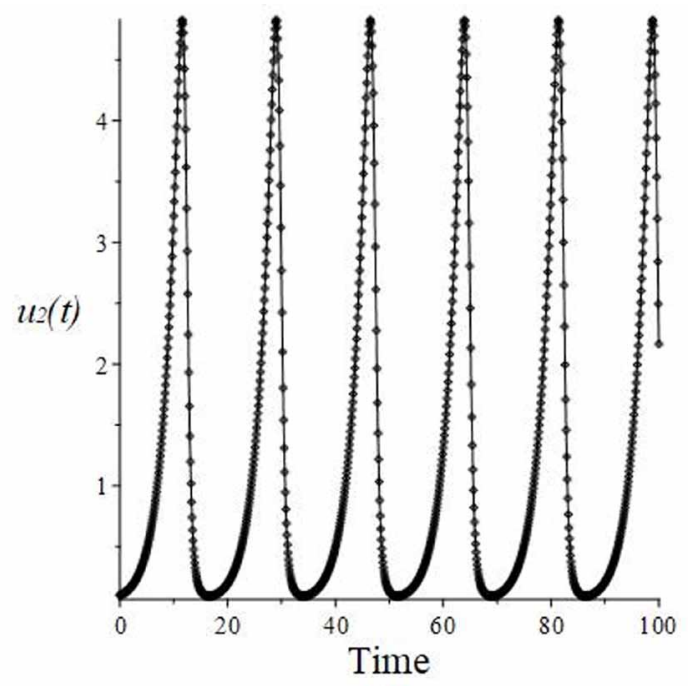

$\alpha_{1}=-0.5, \alpha_{2}=0, \alpha_{3}=0.9, \beta_{1}=0, \beta_{2}=0.02$, and $\beta_{3}=-0.2$,

and the system becomes:

$\frac{d u_{1}(t)}{d t}=-0.5 u_{1}(t)+0.9 u_{1}(t) u_{2}(t)$ 
Figure 3. Both $u_{1}(t)$ and $u_{2}(t)$ as functions of time $t$

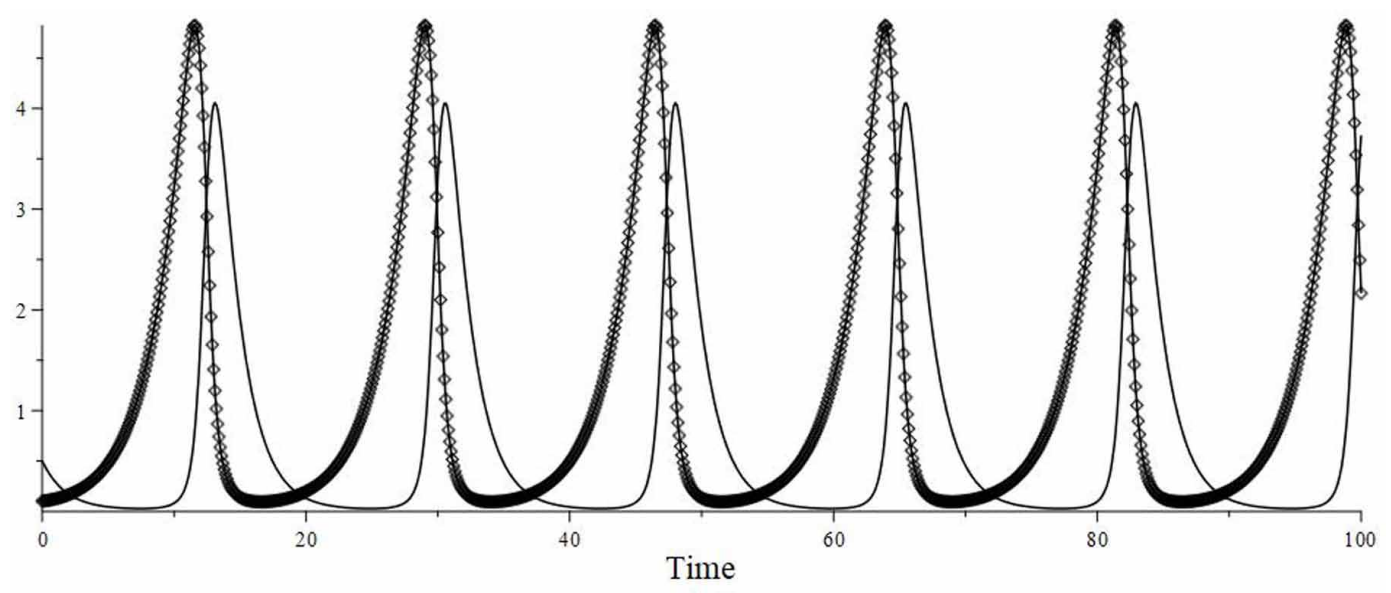

Figure 4. Dynamics of $u_{1}(t)$ and $u_{2}(t)$ shows a cycle

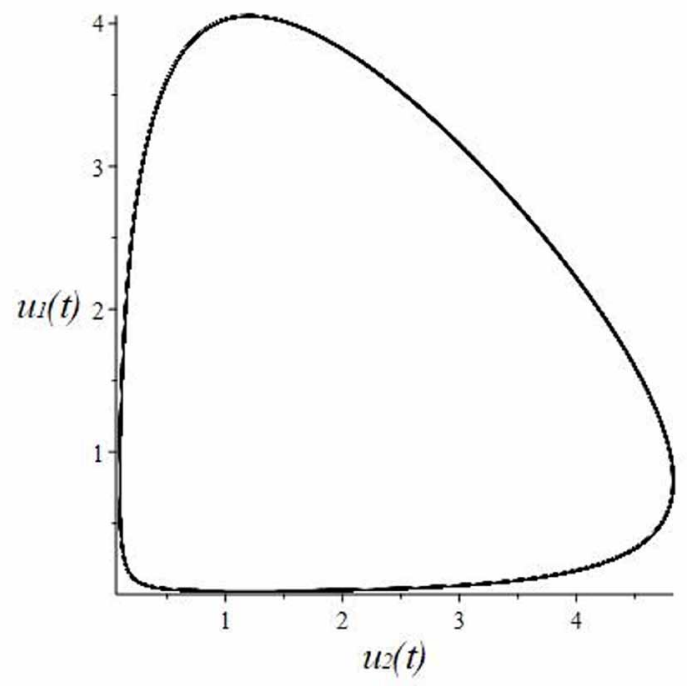

$\frac{d u_{2}(t)}{d t}=0.02 u_{2}(t)-0.2 u_{1}(t) u_{2}(t)$

Different $\alpha$ 's and $\beta$ 's was chosen is to observe the outcome of "down-play" in the role of $u_{2}(t)$. To do that, a change to the parameter $\beta_{2}$ from 2 to 0.02 and $\beta_{3}$ from -1.2 to -0.02 was made. The simulation results are shown in Figures 6 to 10. Figures 6 and 7 record that $u_{1}(t)$ and $u_{2}(t)$ as a function of time $t$, respectively. The graphs of $u_{1}(t)$ and $u_{2}(t)$ are plotted together in Figure 8 .

In Case II, it is also observed that $u_{1}(t)$ and $u_{2}(t)$ are behaving like predator and prey. Some observations and comparison with Case I can be made from Figures 6, 7, and 8:

(1) Both $u_{1}(t)$ and $u_{2}(t)$ are periodic functions. 
Figure 5. Phase portrait analysis of $u_{1}(t)$ and $u_{2}(t)$ shows the direction of the dynamic cycle

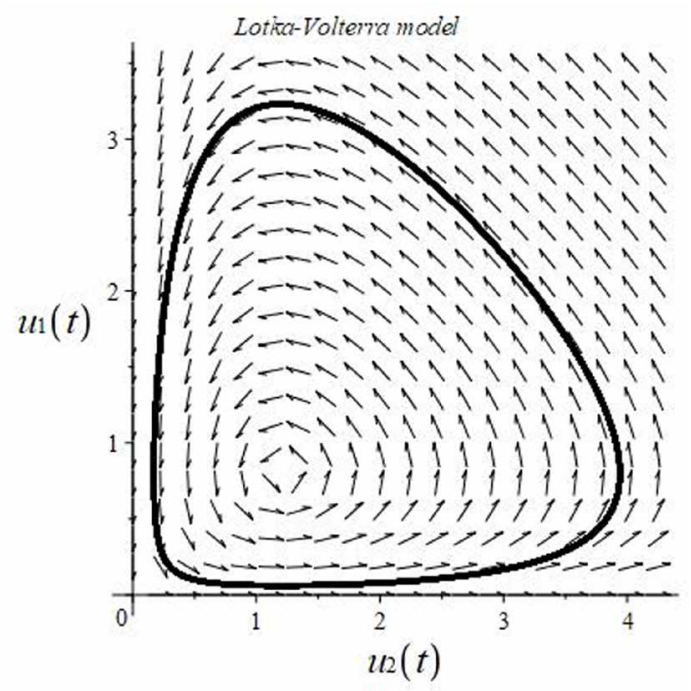

Figure 6. $u_{1}(t)$ as a function of time $\mathbf{t}$

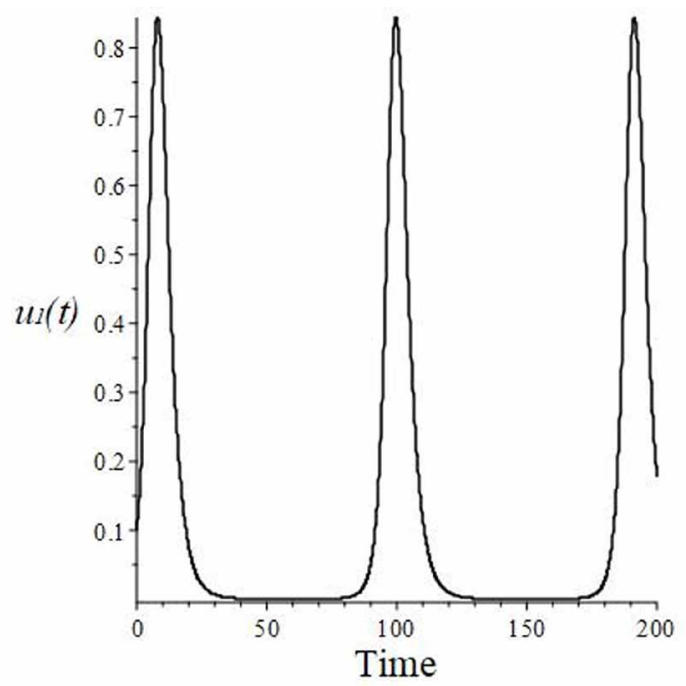

(2) From Figure 8 , it can be observed that $u_{1}(t)$ is heavily depending on $u_{2}(t)$. As soon as $u_{2}(t)$ decreased, then $u_{1}(t)$ quickly plunged down to a zero level.

(3) When $u_{1}(t)$ approached to zero and stay at zero for a period of time, then $u_{2}(t)$ gradually picked up and attains its maximum. There is a "longer" period of time for $u_{1}(t)$ to stay at a "depression" status.

(4) When $u_{1}(t)$ increased, then $u_{2}(t)$ decreased. However, as $u_{2}(t)$ decreased to certain level, then $u_{1}(t)$ also decreased.

(5) This cycle appears repeatedly, which was plotted as $u_{1}(t)$ and $u_{2}(t)$ in Figures 9 and 10. In Figure 9 a dynamical "cycle" is observed, and in Figure 10 the "motion" of the dynamical "cycle" is observed. 
Figure 7. $u_{2}(t)$ as a function of time $\mathbf{t}$

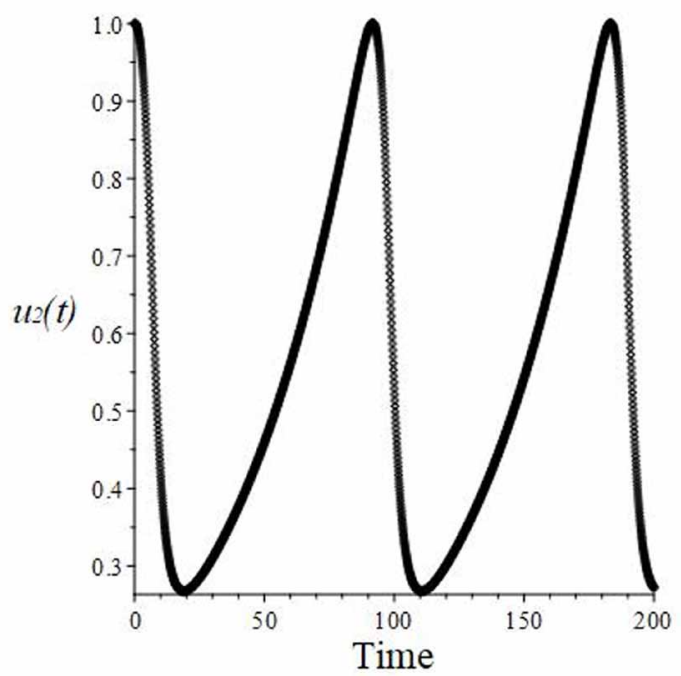

Figure 8. Both $u_{1}(t)$ and $u_{2}(t)$ as functions of time $\mathbf{t}$

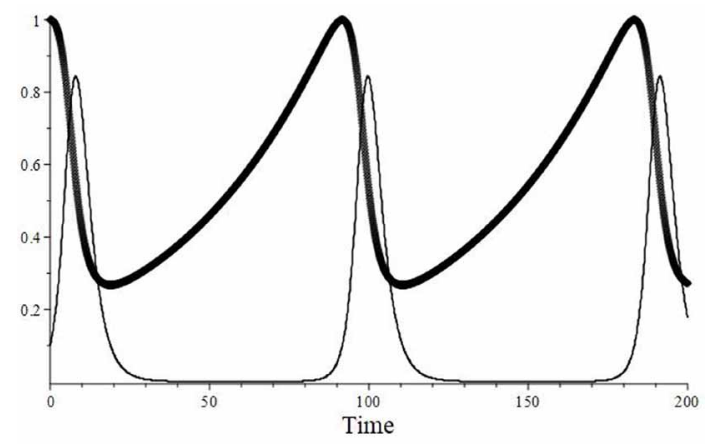

\subsubsection{Case III - Modified Lotka-Volterra Case}

In this simulation, the (classical) Lotka-Volterra dynamical system is modified by choosing $\alpha$ 's and $\beta$ 's to be:

$\alpha_{1}=-0.23, \alpha_{2}=-0.02, \alpha_{3}=0.75, \beta_{1}=0.01, \beta_{2}=0.54$, and $\beta_{3}=-0.4$,

and the dynamical system becomes:

$$
\begin{aligned}
& \frac{d u_{1}(t)}{d t}=-0.23 u_{1}(t)-0.02 u_{2}(t)+0.75 u_{1}(t) u_{2}(t) \\
& \frac{d u_{2}(t)}{d t}=0.01 u_{1}(t)+0.54 u_{2}(t)-0.4 u_{1}(t) u_{2}(t)
\end{aligned}
$$


Figure 9. Dynamics of $u_{1}(t)$ and $u_{2}(t)$

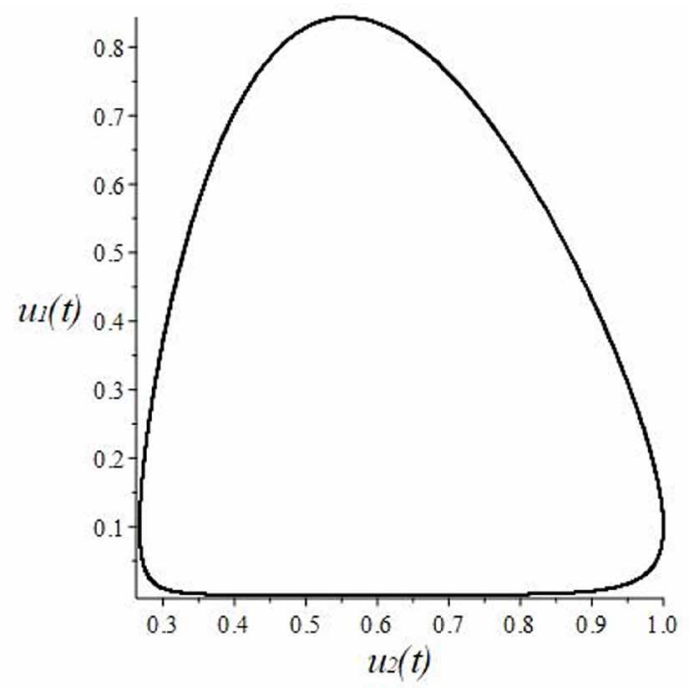

Figure 10. Phase portrait plane analysis of $u_{1}(t)$ and $u_{2}(t)$

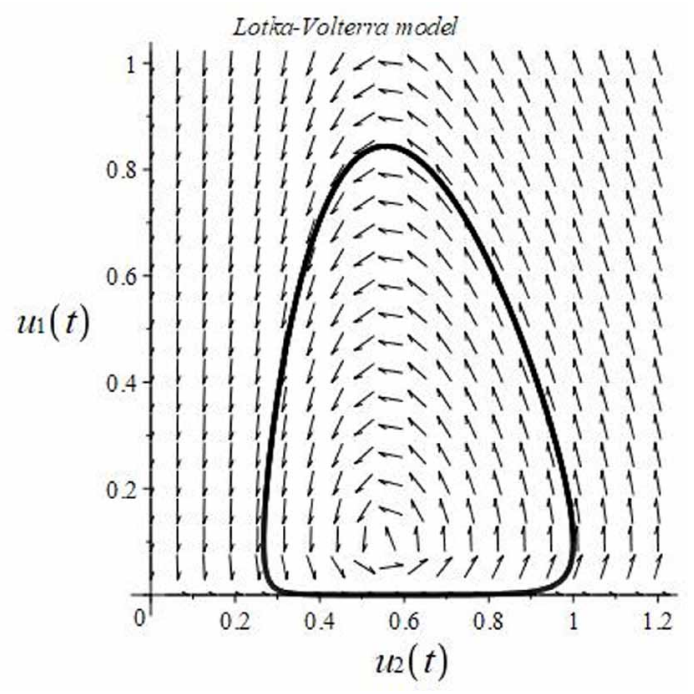

The simulation results are shown in Figures 11 to 15 .

In Case III, a different pattern of the dynamical behavior is observed between $u_{1}(t)$ and $u_{2}(t)$. Some observations and comparison with previous Case I and Case II can be made from Figures 11, 12, and 13:

(1) None of $u_{1}(t)$ and $u_{2}(t)$ are periodic functions. However, both $u_{1}(t)$ and $u_{2}(t)$ share a "decaying" wave pattern. 


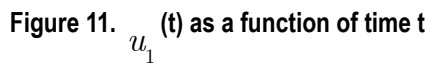

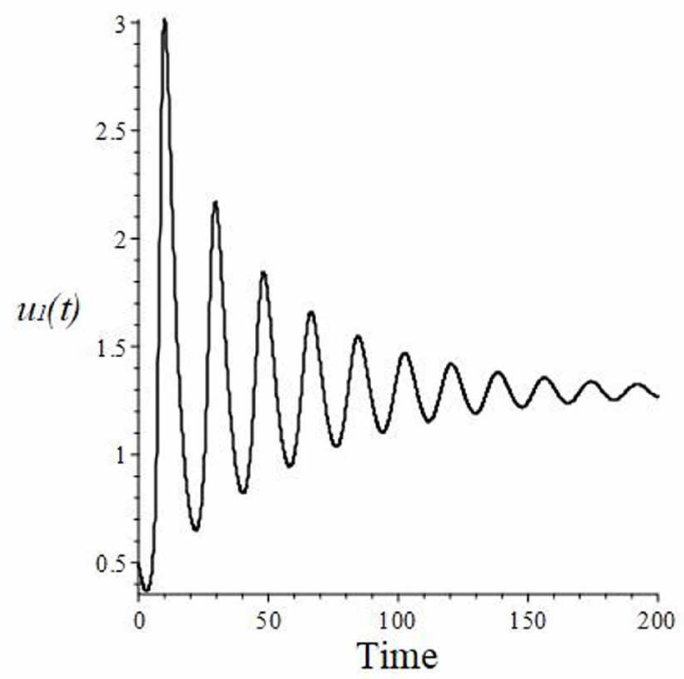

Figure 12. $u_{2}(\mathbf{t})$ as a function of time $\mathbf{t}$

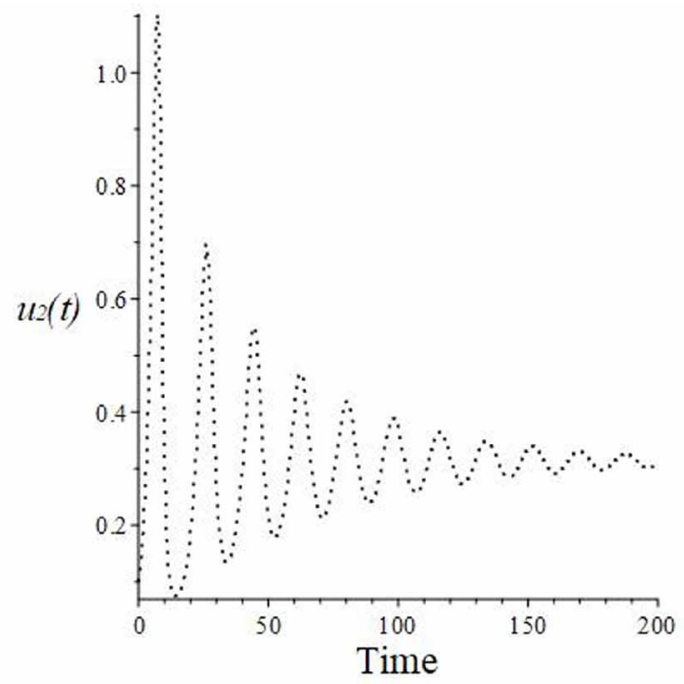

(2) There is still predator-prey behavior between $u_{1}(t)$ and $u_{2}(t)$. That is, $u_{1}(t)$ and $u_{2}(t)$ increase and decrease "conversely". The peak of $u_{1}(t)$ occurs at the valley of $u_{2}(t)$, and so is conversely. Again, $u_{1}(t)$ and $u_{2}(t)$ depend on each other, neither can grow infinitely without the existence of the other.

(3) From Figure 13, it can be seen that $u_{1}(t)$ is always "dominating" $u_{2}(t)$. This should be a very common practice in the oil and gas industry; given in most time, profit maximization is the primary goal of a firm in the oil and gas industry. 
Figure 13. Both $u_{1}(t)$ and $u_{2}(t)$ as functions of time $t$

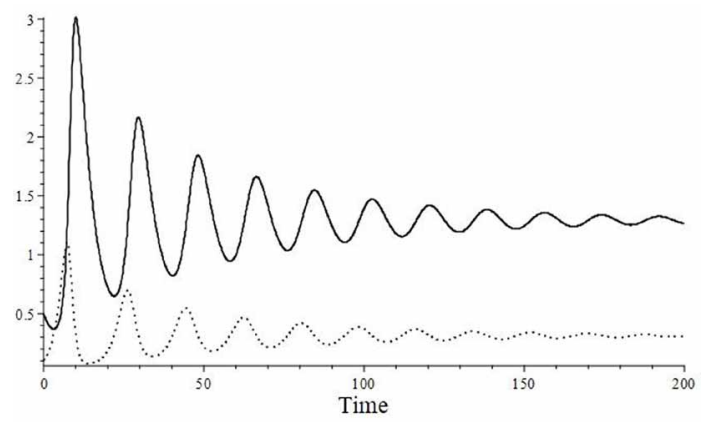

Figure 14. Dynamics of $u_{1}(t)$ and $u_{2}(t)$ reveals

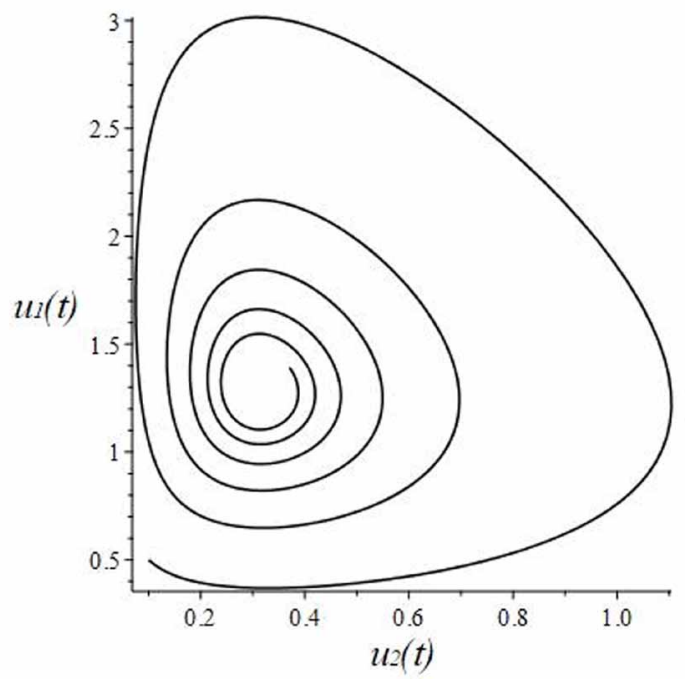

Figure 15. Phase portrait plane analysis a spiral pattern

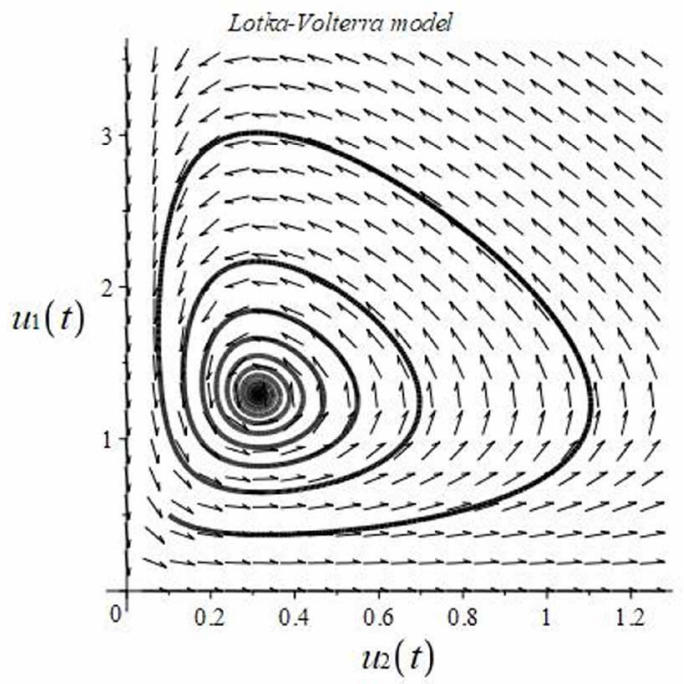


(4) There is NO fixed cycle between $u_{1}(t)$ and $u_{2}(t)$. The dynamics between $u_{1}(t)$ and $u_{2}(t)$ is plotted in Figure 14, and it shows a "spiral" pattern. Eventually $u_{1}(t)$ and $u_{2}(t)$ will attain their "steadystate" status. The "motion" of the dynamical spiral is shown in Figure 15.

\subsubsection{Case IV - Second Modified Lotka-Volterra Case}

In this Case IV simulation, another modified Lotka-Volterra dynamical system is studied by choosing $\alpha$ 's and $\beta$ 's to be

$\alpha_{1}=-0.6, \alpha_{2}=0.1, \alpha_{3}=0.4, \beta_{1}=-0.1, \beta_{2}=0.4$, and $\beta_{3}=-0.6$,

and the system becomes

$$
\begin{aligned}
& \frac{d u_{1}(t)}{d t}=-0.6 u_{1}(t)+0.1 u_{2}(t)+0.4 u_{1}(t) u_{2}(t) \\
& \frac{d u_{2}(t)}{d t}=-0.1 u_{1}(t)+0.4 u_{2}(t)-0.6 u_{1}(t) u_{2}(t)
\end{aligned}
$$

The simulation results are shown in Figures 16 to 20.

In Case IV, a similar pattern is seen of the dynamical behavior between $u_{1}(t)$ and $u_{2}(t)$ as in Case III. The difference between this case and Case III is that the study assigned a "penalty" to $u_{1}(t)$ if $u_{1}(t)$ grew too fast. The penalty is by weighing more to the constant $\alpha_{1}$. In Case III, $\alpha_{1}=-0.23$, then it was changed to $\alpha_{1}=-0.6$ in Case IV. Some observations and comparison with previous Cases I, II, and III could be made from Figures 16, 17, and 18:

None of $u_{1}(t)$ and $u_{2}(t)$ are periodic functions. However, like in Case III, both $u_{1}(t)$ and $u_{2}(t)$ share a "decaying" wave pattern.

Figure 16. $u_{1}(t)$ as a function of time $t$

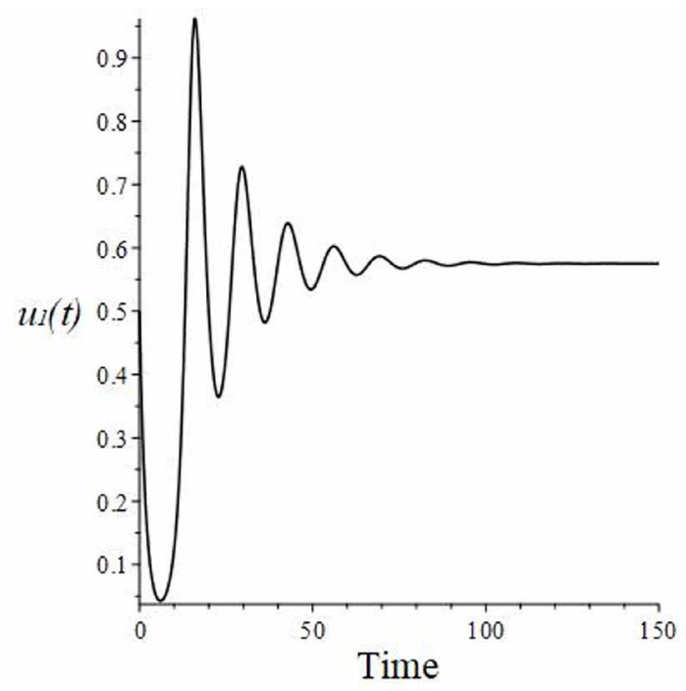


Figure 17. $u_{2}(t)$ as a function of time $t$

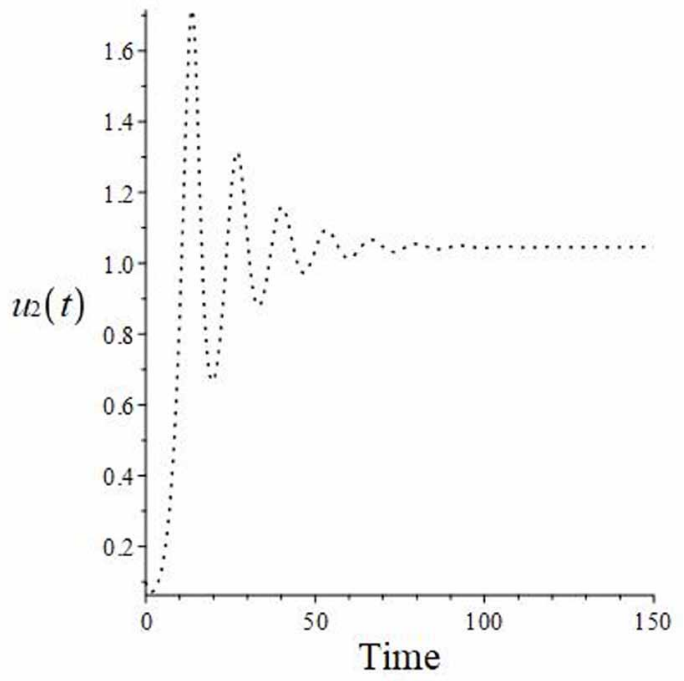

(1) There is still predator-prey behavior between $u_{1}(t)$ and $u_{2}(t)$. That is, $u_{1}(t)$ and $u_{2}(t)$ increase and decrease "conversely". The peak of $u_{1}(t)$ occurs at the valley of $u_{2}(t)$, and so is conversely. Again, $u_{1}(t)$ and $u_{2}(t)$ depend on each other, neither can grow infinitely without the existence of the other.

(2) From Figure 18 it can be seen that $u_{1}(t)$ is always "dominated" by $u_{2}(t)$. This is because it was assigned assign a "penalty" to $u_{1}(t)$ if $u_{1}(t)$ grows too fast. This does not seem to be a common practice in the oil and gas industry; however, it may happen in some situation if a firm has made a serious mistake on damaging environment, then the fi must pay more price on correcting the mistake.

Figure 18. Both $u_{1}(t)$ and $u_{2}(t)$ as functions of time $t$

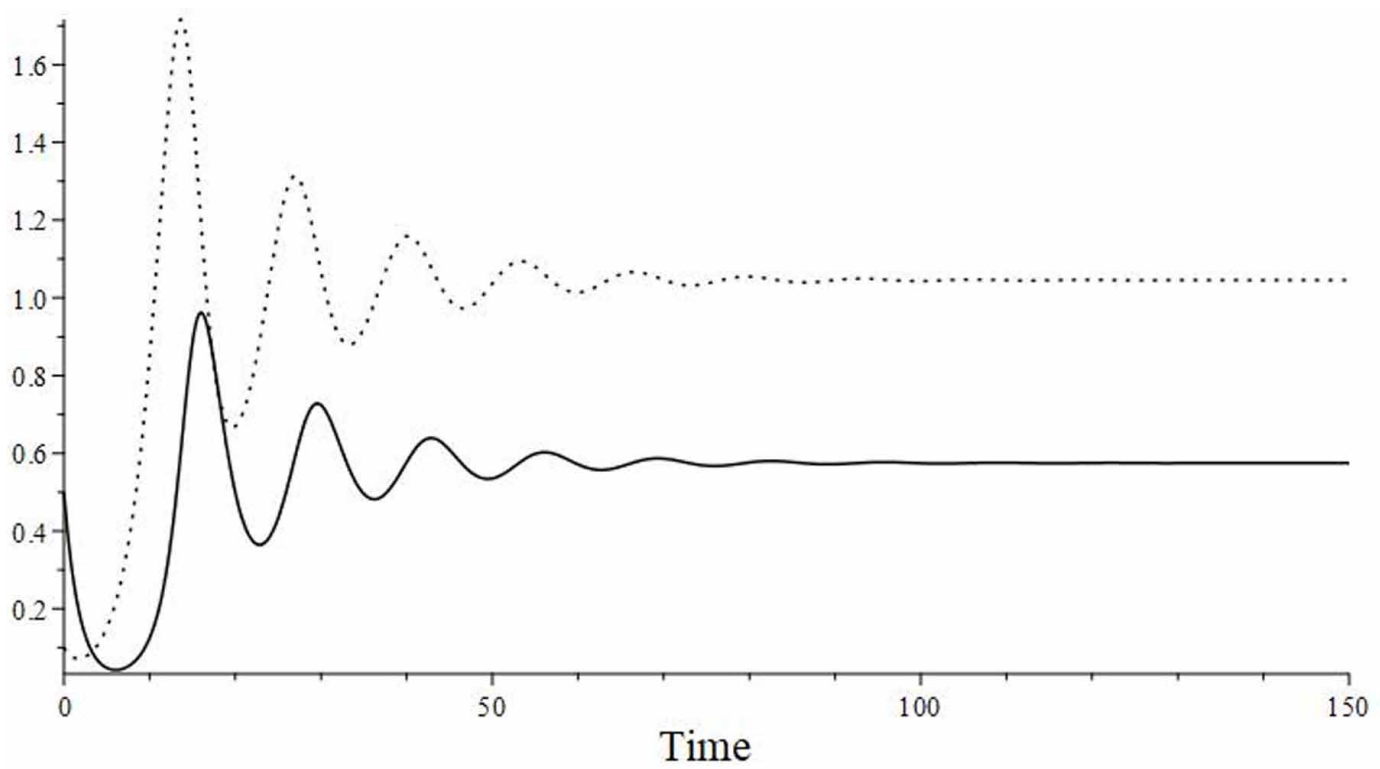


(3) There is NO fixed cycle between $u_{1}(t)$ and $u_{2}(t)$. The dynamics between $u_{1}(t)$ and $u_{2}(t)$ is plotted in Figure 19, and it shows a "spiral" pattern. Eventually $u_{1}(t)$ and $u_{2}(t)$ will attain their "steadystate" status. The "motion" of the dynamical spiral is shown in Figure 20. This spiral pattern is very alike in Case III, but in Case IV here it seems that "steady-state" status can be reached faster than in Case III.

Figure 19. Dynamics of $u_{1}(t)$ and $u_{2}(t)$

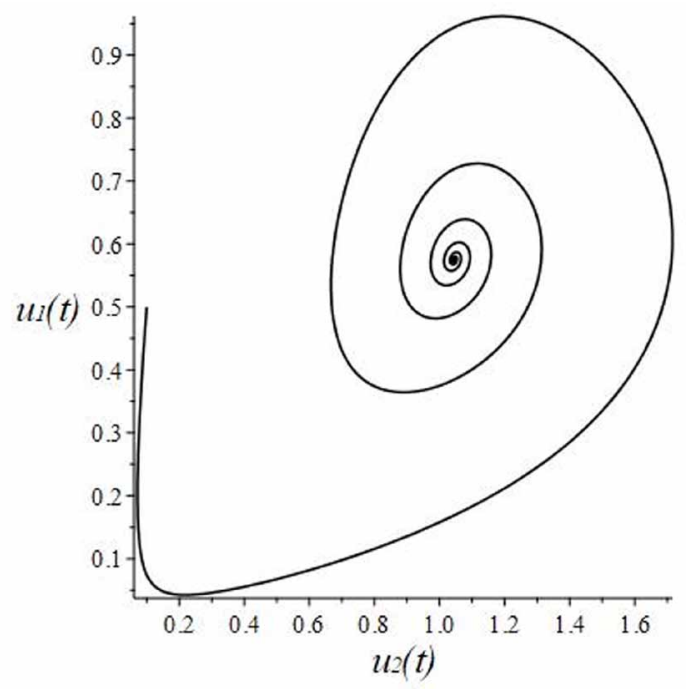

Figure 20. Phase portrait analysis of $u_{1}(t)$ and $u_{2}(t)$ shows a spiral pattern

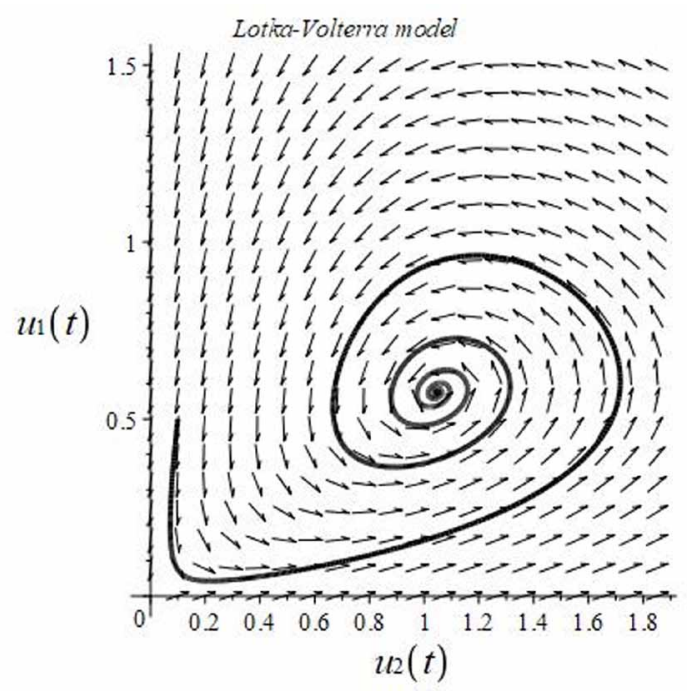




\section{CONCLUSION}

The study's first model provides the insights that optimal allocation process is determined by multiple dimensions including a firm's competitive ranking among its competitors, industrial consent on the concurrent rate of returns on investment, the projected demand of oil and gas in the future and change in environmental compliance cost. In addition to characterizing the intricate relationship of the multiple dimensions, the model adds the robustness of the optimal allocation process by providing binding conditions of the set of solutions. The second model was a dynamical analysis for the traceoffs between innovative technology and investment on incumbent assets. The analysis is a qualitative one; however, it does provide some insights for future quantitative analysis. Collection of more data is needed for a future empirical investigation. The data could be used to give a proper estimation of the constants of $\alpha$ 's and $\beta$ 's so that the simulation can be more realistic.

The two proposed models capture the communally competitive and cyclically evolvement process. However, they provide two different types of analysis between technological innovation and upgrading. The optimal model is a quantitative analysis which leads to an exact "optimal outcomes." However, the exact solution obtained from the optimal model depends on the specific cost function $H\left(u_{1}, u_{2}\right)$, (see Equation 7). Not all cost function may lead to an exact set of solution. Then the predator-prey model comes in to provide another type of analysis, which is a qualitative analysis. This qualitative analysis offers further insights of the dynamical behavior between technological innovation and upgrading pursuant to the change of time cycle. Technological advancement is critical to have a sustainable business in oil and gas industry. It helps to gain competitive advantage of certain dimensions of a particular business and generating new values for customers as well as the firm itself. This study, thus, has implications for managers for formulate technological investment decisions based on the intricate relationship of key elements and the cyclical evolvement between two feasible options (upgrading and innovation). 


\section{REFERENCES}

Adner, R., \& Kapoor, R. (2010). Value creation in innovation ecosystems: How the structure of technological interdependence affects firm performance in new technology generations. Strategic Management Journal, 31(3), 306-333. doi:10.1002/smj.821

Agnolucci, P., \& Arvanitopoulos, T. (2019). Industrial characteristics and air emissions: Long-term determinants in the UK manufacturing sector. Energy Economics, 78, 546-566. doi:10.1016/j.eneco.2018.12.005

Alam, M. S., Atif, M., Chien-Chi, C., \& Soytaş, U. (2019). Does corporate R\&D investment affect firm environmental performance? Evidence from G-6 countries. Energy Economics, 78, 401-411. doi:10.1016/j. eneco.2018.11.031

Alaska Department of Environmental Conservation v. Environmental Protection Agency. (2004). https:// en.wikipedia.org/wiki/Alaska_Department_of_Environmental_Conservation_v._EPA

Ambec, S., Cohen, M. A., Elgie, S., \& Lanoie, P. (2013). The Porter hypothesis at 20: Can environmental regulation enhance innovation and competitiveness? Review of Environmental Economics and Policy, 7(1), 2-22. doi:10.1093/reep/res016

American Petroleum Industry (API). (2018). Economy Fact Sheet. https://www.api.org/news-policy-and-issues/ taxes/oil-and-natural-gas-contribution-to-us-economy-fact-sheet

Arthur, W. B. (2009). The nature of technology: What it is and how it evolves. Free Press.

Arya, A., Mittendorf, B., \& Ramanan, R. N. (2019). Beyond profits: The rise of dual-purpose organizations and its consequences for disclosure. The Accounting Review, 94(1), 25-43. doi:10.2308/accr-52166

Bagnoli, M., \& Watts, S. (2003). Selling to socially responsible consumers: Competition and the private provision of public goods. Journal of Economics \& Management Strategy, 12(3), 419-445. doi:10.1162/105864003322309536

Baker, M., \& Wurgler, J. (2007). Investor sentiment in the stock market. The Journal of Economic Perspectives, 21(2), 129-151. doi:10.1257/jep.21.2.129

Bartov, E., Marra, A., \& Momente, F. (2021). Corporate Social Responsibility and the Market Reaction to Negative Events: Evidence from Inadvertent and Fraudulent Restatement Announcements. The Accounting Review, 96(2), 81-106. doi:10.2308/tar-2018-0281

Beake, R., Cole, D., \& Gait, A. (2020). Do we need an 'Energy System Architect'? https://www.atkinsglobal. com/our-priorities/engineering-net-zero

Bénabou, R., \& Tirole, J. (2011). Identity, morals, and taboos: Beliefs as assets. The Quarterly Journal of Economics, 126(2), 805-855. doi:10.1093/qje/qjr002 PMID:22073409

Bento, N., Wilson, C., \& Anadon, L. D. (2018). Time to get ready: Conceptualizing the temporal and spatial dynamics of formative phases for energy technologies. Energy Policy, 119, 282-293. doi:10.1016/j. enpol.2018.04.015

Bhowmik, C., Kaviani, M. A., Ray, A., \& Ocampom, L. (2000). An integrated entropy-TOPSIS methodology for evaluating green energy sources. International Journal of Business Analytics, 7(3), 44-70. doi:10.4018/ IJBAN.2020070104

British Petroleum. (2019). Statistical review of world energy. https://www.bp.com/en/global/corporate/energyeconomics/statistical-review-of-world-energy.html

Bromberger, A. R. (2011). A new type of hybrid. Stanford Social Innovation Review, 9(2), 49-53.

Carmichael, R. (2019). Behaviour change, public engagement and Net Zero. A report for the Committee on Climate Change. http://www.imperial.ac.uk/icept/publications/

Chandrasekaran, D., Arts, J. W., Tellis, G. J., \& Frambach, R. T. (2013). Pricing in the international takeoff of new products. International Journal of Research in Marketing, 30(3), 249-264. doi:10.1016/j.ijresmar.2012.09.008

Davidson, R. H., Dey, A., \& Smith, A. J. (2019). CEO materialism and corporate social responsibility. The Accounting Review, 94(1), 101-126. doi:10.2308/accr-52079 
Deloitte, LLP. (2015). Oil and gas reality check 2015: A look at the top issues facing the oil and gas sector. https://www2.deloitte.com/bg/en/pages/energy-and-resources/articles/oil-gas-reality-check.html

DeMarzo, P. M., \& Duffie, D. (1995). Corporate incentives for hedging and hedge accounting. Review of Financial Studies, 8(3), 743-771. doi:10.1093/rfs/8.3.743

Devaney, R. (2018). An introduction to chaotic dynamical systems. CRC Press. doi:10.4324/9780429502309

Diaz, R., Behr, J. G., Landaeta, R., Longo, F., \& Nicoletti, L. (2015). Modeling energy portfolio scoring: A simulation framework. International Journal of Business Analytics, 2(4), 1-22. doi:10.4018/IJBAN.2015100101

Duarte, R., \& Serrano, A. (2021). Environmental analysis of structural and technological change in a context of trade expansion: Lessons from the EU enlargement. Energy Policy, 150, 112142. doi:10.1016/j.enpol.2021.112142

Fouquet, R. (2016). Historical energy transition speed, prices, and system transformation. Energy Research \& Social Science, 22, 7-12. doi:10.1016/j.erss.2016.08.014

Freeman, R. E. (2010). Strategic management: A stakeholder approach. Cambridge University Press. doi:10.1017/ CBO9781139192675

Friedman, H. L., \& Heinle, M. S. (2016). Taste, information, and asset prices: Implications for the valuation of CSR. Review of Accounting Studies, 21(3), 740-767. doi:10.1007/s11142-016-9359-x

Geels, F. W. (2002). Technological transitions as evolutionary reconfiguration processes: A multi-level perspective and a case-study. Research Policy, 31(8-9), 1257-1274. doi:10.1016/S0048-7333(02)00062-8

Geels, F. W., Sovacool, B. K., Schwanen, T., \& Sorrell, S. (2017). The socio-technical dynamics of low-carbon transitions. Joule, 1(3), 463-479. doi:10.1016/j.joule.2017.09.018

Gonzalez-Benito, J., \& Gonzalez-Benito, O. (2005). Environmental proactivity and business performance: An empirical analysis. Omega, 33(1), 1-15. doi:10.1016/j.omega.2004.03.002

Gotschol, A., Giovanni, P. D., \& Vinzi, V. E. (2014). Is environmental management an economically sustainable business? Journal of Environmental Management, 144, 73-82. doi:10.1016/j.jenvman.2014.05.001 PMID:24921964

Gox, R. F., \& Schiller, U. (2006). An economic perspective on transfer pricing. Handbooks of Management Accounting Research, 2, 673-695. doi:10.1016/S1751-3243(06)02009-8

Gray, W. B., \& Shadbegian, R. J. (1998). Environmental regulation, investment timing, and technology choice. The Journal of Industrial Economics, 46(2), 235-256. doi:10.1111/1467-6451.00070

Gross, R., Hanna, R., Gambhir, A., Heptostall, P., \& Speirs, J. (2018). How long does innovation and commercialization in the energy sectors take? Historical case studies of the timescale from invention to widespread commercialization in energy supply and end use technology. Energy Policy, 123, 682-699. doi:10.1016/j. enpol.2018.08.061

Grubler, A., Wilson, C., \& Nemet, G. (2016). Apples, oranges, and consistent comparisons of the temporal dynamics of energy transitions. Energy Research \& Social Science, 22, 18-25. doi:10.1016/j.erss.2016.08.015

Hansmann, H. (1980). The role of nonprofit enterprise. The Yale Law Journal, 89(5), 835-902. doi:10.2307/796089

Hart, O. (2003). Incomplete contracts and public ownership: Remarks, and an application to public-private partnerships. Economic Journal (London), 113(486), 69-76. doi:10.1111/1468-0297.00119

Hassan, A. S., Sun, Y. X., \& Wang, Z. H. (2020). Optimization techniques applied for optimal planning and integration of renewable energy sources based on distributed generation: Recent trends. Cogent Engineering, 7(1), 1766394. doi:10.1080/23311916.2020.1766394

Hino, Y., \& Zennyo, Y. (2017). Corporate social responsibility and strategic relationships. International Review of Economics, 64(3), 231-244. doi:10.1007/s12232-016-0267-y

Hsu, C. C., Tan, K. C., Zailani, S. H. M., \& Jayaraman, V. (2013). Supply chain drivers that foster the development of green initiatives in an emerging economy. International Journal of Operations \& Production Management, 33(6), 656-688. doi:10.1108/IJOPM-10-2011-0401 
Hug, V. (2009). Bridging the Valley of Death: public support for commercialisation of eco-innovation. European Commission, Directorate General Environment, Final Report. https://ec.europa.eu/environment/enveco/ rd_innovation/pdf/studies/bridging_valley_report.pdf

International Energy Agency (IEA). (2020). The oil and gas industry in energy transitions; insights from IEA analysis. https://iea.blob.core.windows.net/assets/4315f4ed-5cb2-4264-b0ee-2054fd34c118/The_Oil_and_Gas_ Industry_in_Energy_Transitions.pdf

Jaffe, A. B., \& Palmer, K. (1997). Environmental regulation and innovation: A panel data study. The Review of Economics and Statistics, 79(4), 610-619. doi:10.1162/003465397557196

Jensen, M. C. (2001). Value maximization, stakeholder theory, and the corporate objective function. Journal of Applied Corporate Finance, 14(3), 8-21. doi:10.1111/j.1745-6622.2001.tb00434.x

Kanodia, C., Mukherji, A., Sapra, H., \& Venugopalan, R. (2000). Hedge disclosures, future prices, and production distortions. Journal of Accounting Research, 38, 53-82. doi:10.2307/2672908

Kanter, R. M. (2011). How great companies think differently. Harvard Business Review, 89(11).

Lanjouw, J. O., \& Mody, A. (1996). Innovation and the international diffusion of environmentally responsive technology. Research Policy, 25(4), 549-571. doi:10.1016/0048-7333(95)00853-5

Library of Congress. (2021). Oil and gas industry: A research guide. https://guides.loc.gov/oil-and-gas-industry/ news

Ma, F. P., Guo, X. C., \& Cha, N. (2011). Research on the impact of environmental regulation on technological innovation performance: An empirical test based on resource-based enterprises. Science and Technology Magazine, 8(32), 87-92.

Magat, W. A. (1978). Pollution control and technological advance: A dynamic model of the firm. Journal of Environmental Economics and Management, 5(1), 1-25. doi:10.1016/0095-0696(78)90002-5

Matsummura, T. (1998). Partial privatization in mixed duopoly. Journal of Public Economics, 70(3), 473-483. doi:10.1016/S0047-2727(98)00051-6

McKinsey \& Company. (2021, January). Global energy perspective 2021. https://www.mckinsey.com/ /media/ McKinsey/Industries/Oil\%20and\%20Gas/Our\%20Insights/Global\%20Energy\%20Perspective\%202021/GlobalEnergy-Perspective-2021-final.pdf

Melumad, N., Weyns, G., \& Ziv, A. (1999). Comparing alternative hedge accounting standards: Shareholders' perspective. Review of Accounting Studies, 4(3), 265-292. doi:10.1023/A:1009638302403

Munsamy, M., Telukdarie, A., \& Dhamija, P. (2020). Logistics 4.0 Energy Modeling. International Journal of Business Analytics, 7(1), 98-121. doi:10.4018/IJBAN.2020010106

Naughton, J. P., Wang, C., \& Yeung, I. (2019). Investor sentiment for corporate social performance. The Accounting Review, 94(4), 401-420. doi:10.2308/accr-52303

Nelson, S., \& Allwood, J. M. (2021). The technological and social timelines of climate mitigation: Lessons from 12 past transitions. Energy Policy, 152, 112155. doi:10.1016/j.enpol.2021.112155

Pan, X., Ai, B., Li, C. Y., Pan, X., \& Yan, Y. B. (2019). Dynamic relationship among environmental regulation, technological innovation and energy efficiency based on large scale provincial panel data in China. Technological Forecasting and Social Change, 144, 428-435. doi:10.1016/j.techfore.2017.12.012

Perkins, R., \& Neumayer, E. (2005). The international diffusion of new technologies: A multitechnology analysis of latecomer advantage and global economic integration. Annals of the Association of American Geographers, 95(4), 789-808. doi:10.1111/j.1467-8306.2005.00487.x

Porter, M. E. (1990). The competitive advantage of nations. Competitive Intelligence Review, 1(1), 14-14. doi:10.1002/cir.3880010112

Porter, M. E., \& Kramer, M. R. (2006). Strategy and society: The link between corporate social responsibility and competitive advantage. Harvard Business Review, 84(12), 78-92. PMID:17183795 
Porter, M. E., \& Vanderlinde, C. (1995). Green and competitive: Ending the stalemate. Harvard Business Review, 73(6), 120-134.

Rogers, E. M. (2003). Diffusion of Innovation. Free Press.

Schediac, R., Abouchakra, R., Hammami, M., \& Najjar, M. R. (2008). Public-Private Partnerships: A New Catalyst for Economic Growth. Booz \& Company.

Schelling, T. C. (1960). The Strategy of Conflict. Harvard University Press.

Shahbaz, M., Karaman, A., Kilic, M., \& Uyar, A. (2020). Board attributes, CSR engagement, and corporate performance: What is the nexus in the energy sector? Energy Policy, 143, 111582. doi:10.1016/j.enpol.2020.111582

Shen, K. R., Jin, G., \& Fang, X. (2017). Does environmental regulation cause pollution to transfer nearby? Economic Research Journal, 5, 44-59.

Smil, V. (2016). Examining energy transitions: A dozen insights based on performance. Energy Research \& Social Science, 22, 194-197. doi:10.1016/j.erss.2016.08.017

Sovacool, B. K. (2016). How long will it take? Conceptualizing the temporal dynamics of energy transitions. Energy Research \& Social Science, 13, 202-215. doi:10.1016/j.erss.2015.12.020

Stark, C., \& Thompson, M. (2019). Net zero: The UK's contribution to stopping global warming. https://www. theccc.org.uk/wp-content/uploads/2019/05/Net-Zero-The-UKs-contribution-to-stopping-global-warming.pdf

Stevens, P. A., Batty, W. J., Longhurst, P. J., \& Drew, G. H. (2012). A critical review of classification of organizations in relation to the voluntary implement of environmental management system. Journal of Environmental Management, 112, 206-212. doi:10.1016/j.jenvman.2012.08.037 PMID:23037315

Strogatz, S. H. (1994). Nonlinear dynamics and chaos with applications to physics, biology, chemistry, and engineering. Academic Press.

Tang, T. (2018). Explaining technological change in the U.S. wind industry: Energy policies, technological learning, and collaboration. Energy Policy, 120, 197-212. doi:10.1016/j.enpol.2018.05.016

Tung, A., Baird, K., \& Schoch, H. (2014). The relationship between organisational factors and the effectiveness of environmental management. Journal of Environmental Management, 144, 186-196. doi:10.1016/j. jenvman.2014.05.025 PMID:24952341

Vickers, J. (1985). Delegation and the theory of the firm. Economic Journal (London), 95, $138-147$. doi: $10.2307 / 2232877$

Walte, I., \& Ugelow, J. L. (1979). Environmental policies in developing countries. Ambio, 8, 102-109.

Weyant, J. P. (2011). Accelerating the development and diffusion of new energy technologie: Beyond the "valley of death". Energy Economics, 33(4), 674-682. doi:10.1016/j.eneco.2010.08.008

Wilson, C., Grubler, A., Gallagher, K. S., \& Nemet, G. F. (2012). Marginalization of end-use technologies in energy innovation for climate protection. Nature Climate Change, 2(11), 780-788. doi:10.1038/nclimate1576

Xie, M. H., Guo, J. X., \& Wang, J. (2016). Environmental regulation, technological innovation and enterprises' transformation - based on Shanghai and Shenzhen listed heavy-pollution enterprises. $R$ \& D Management, 01, 84-94.

Yurtsever, O., \& Firat, S. U. (2019). An evaluation on carbon footprint indicators in Turkey located banks and worldwide banks. International Journal of Business Analytics, 6(4), 74-95. doi:10.4018/IJBAN.2019100106

Zailani, S., Jeyaraman, K., Vengadasan, G., \& Premkumar, R. (2012). Sustainable supply chain management (SSCM) in Malaysia: A survey. International Journal of Production Economics, 140(1), 283-294. doi:10.1016/j. ijpe.2012.02.008

Zeng, A., Feng, Z. B., \& Zhang, Q. (2016). Geographical location, environmental regulation, and enterprise innovation transformation. Journal of Financial Economics, 9, 87-98. 
Cathy Zishang Liu has a PhD in Accounting. Her research interest focuses on financial accounting reporting, auditing and corporate governance issues. She published her research articles on national and international academic journals. She is the recipient of the International Association for Accounting Education and Research (IAAER) grant and University of Houston Downtown Organized Research and Creative Activities Committees (ORCA) grant. She was identified as "the one person at UHD who has made the most significant, positive contribution to their education" in Senior Survey of the UHD students.

Youn-Sha Chan has a Ph.D. in Applied Mathematics. He has published some work on partial differential equations in solid mechanics, and his research also includes mathematical modeling in advanced material and biomechanics. In 2014 he received an Army Research Office grant on the topic "Optical Measurements and Advanced Material Modeling", and in 2016 he also was awarded an REU (Research Experiences for Undergraduates) grant from NSF (National Science Foundation). 